\title{
The method of processing of initial climatic data for systems energy studies with renewable energy sources
}

\author{
Dmitriy Karamov ${ }^{1}$, Sergey Perzhabinsky ${ }^{1}$ \\ ${ }^{1}$ Melentiev Energy Systems Institute, Russia
}

\begin{abstract}
The article presents the method of preparing of initial meteorological information for system energy research. Method and algorithm is based on long-term meteorological observations. Open access observations can be obtained for any territory. The processing of these observations is based on the chronological method of calculation and the theory of statistics. As a result, long-term array of climate information is formed with discrete step of one hour. This array of climate information can be used for various problems in the energy sector.
\end{abstract}

\section{Introduction}

Development of scientific and technological progress encourages researchers around the world to consider the complex energy challenges. The complexity is characterized by a large number of elements, relations, properties of objects and other indicators. Moreover, modern studies use detailed mathematical models of the elements of generation, transmission, distribution, accumulation and energy consumption. This allows precision determination of the regime parameters of the energy system.

To increase the precision of the results of the study of energy systems with renewable energy sources, it is necessary to use detailed climate information. Such information should describe as precisely as possible the climatic parameters in the territory under consideration. Moreover, such information should be freely available and in the open access.

The purpose of this article is to demonstrate the method and algorithm for a detailed analysis of climatic parameters for any territory of the Earth. The first part of the article describes an open source where you can take long-term meteorological observations for any territory. The second part describes the processing algorithm and software. The third part presents the results and conclusion.

\section{Long-term meteorological observation data}

Long-term meteorological observations is detailed information. These climatic arrays dynamic, as each discrete step $(0.5,1,3$ hours $)$ is complemented by new information.

The structure of such climatic arrays is strictly determined by the international meteorological code. Meteorological stations located on land and in the coastal zone use the code FM 12 Synop. Automatic meteorological stations located at airports use a code METAR.

The authors of the article in their studies use data taken from the source RP5 [1]. The latest observational data in FM 12 SYNOP format is available on the website eight times a day, every three hours. The latest observations in METAR format appear on the website once or twice per hour, approximately in 10 minutes after weather observations have been made at the weather station

Currently our website provides weather forecasts for 172500 locations, as well as observational data, reported from 10400 FM 12 SYNOP weather stations, 5400 METAR weather stations and 250 coastal stations

The advantage of this source of meteorological information is that all information is provided with open access. Moreover, you can choose from which weather station (FM 12 Synop, METAR, coastal stations or unofficial weather station) you can get information.

\section{Processing of long-term meteorological observations}

Long-term meteorological observations are processed according to the following algorithm.

1. Classification of the array. At this stage, the definition of the format and structure of the array.

2. Data processing. Identify missing information and inaccuracies. This stage is based on the chronology of information fixation. If there is missing information, then the available years are compared with each other. The data of the most similar year fill in the missing information. Practice has shown that this approach is justified. This stage forms the initial array of environmental parameters.

3. Calculation of the albedo the Earth's surface and clouds.

* Corresponding author: dmitriy.karamov@mail.ru 
4. Formation of arrays of wind speed and direction.

5. Based on WOURDC and AERONET sources, formed array of the ozone layer, the thickness of water vapor in the atmosphere, etc. Calculation of astronomical parameters (sunrise, zenith sunset).

6. Direct, diffuse, reflected and summary solar radiation is calculated using the Iqbal-Kasten / Czeplak model $[2,3]$.

7. The final array of environmental parameters. The array includes wind speed and direction, solar radiation, temperature, density, humidity, pressure and many other parameters.

Processing of long-term meteorological observations is performed on a software "Local analysis of environmental parameters and solar radiation». The software is adapted for processing long-term meteorological observations with both the FM 12 Synop code and METAR [4, 5].

\section{Results}

The village of Uzury located on the island of Olkhon was chosen as the object of study. Olkhon Island is located in the central part of Lake Baikal.

In the village of Uzury there is a meteorological station. This station records meteorological information every three hours. The format of the data record corresponds to the code FM 12 Synop. The number of years of meteorological observations is 12 .

Figures 1 and 2 show solar radiation in the village of Uzury for 12 years.

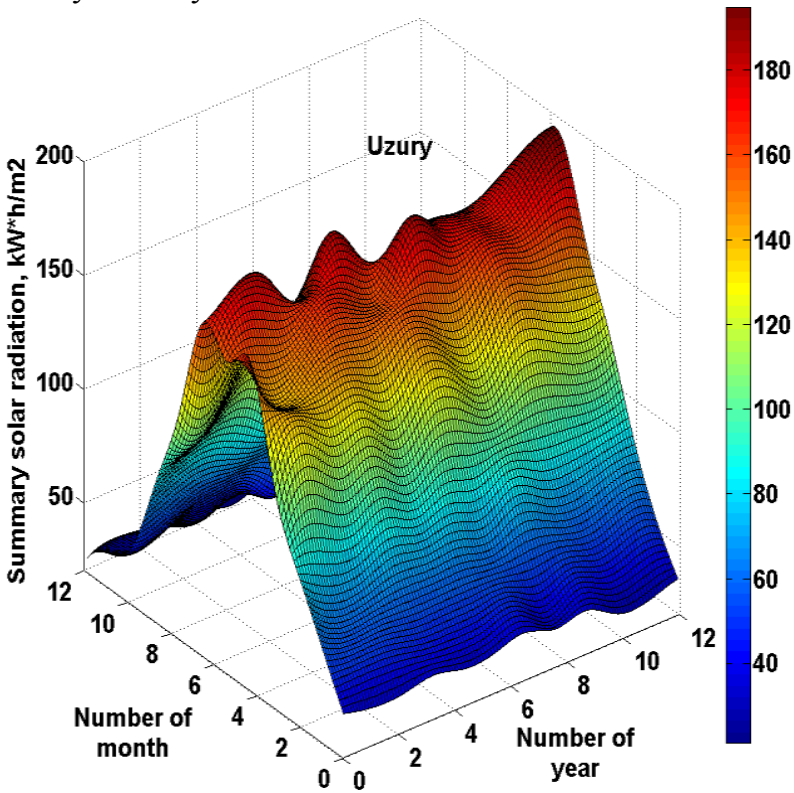

Fig. 1. Summary solar radiation in the village of Uzury according to 12 years of meteorological observations.

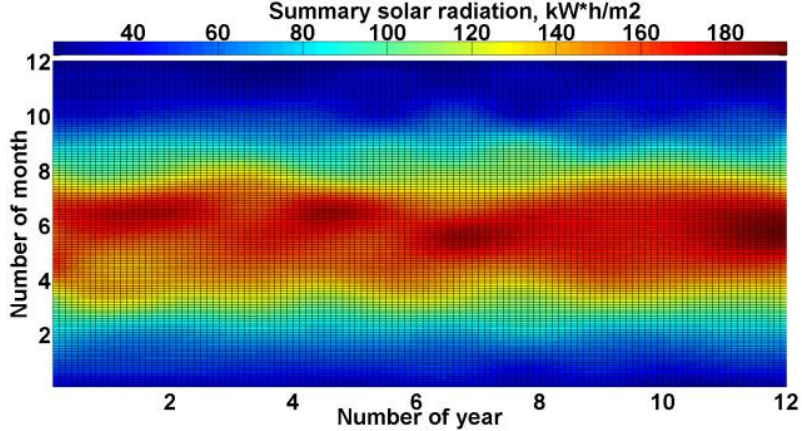

Fig. 2. Summary solar radiation in the village of Uzury according to 12 years of meteorological observations.

Figure 3 shows the average monthly wind speed in the village of Uzury.

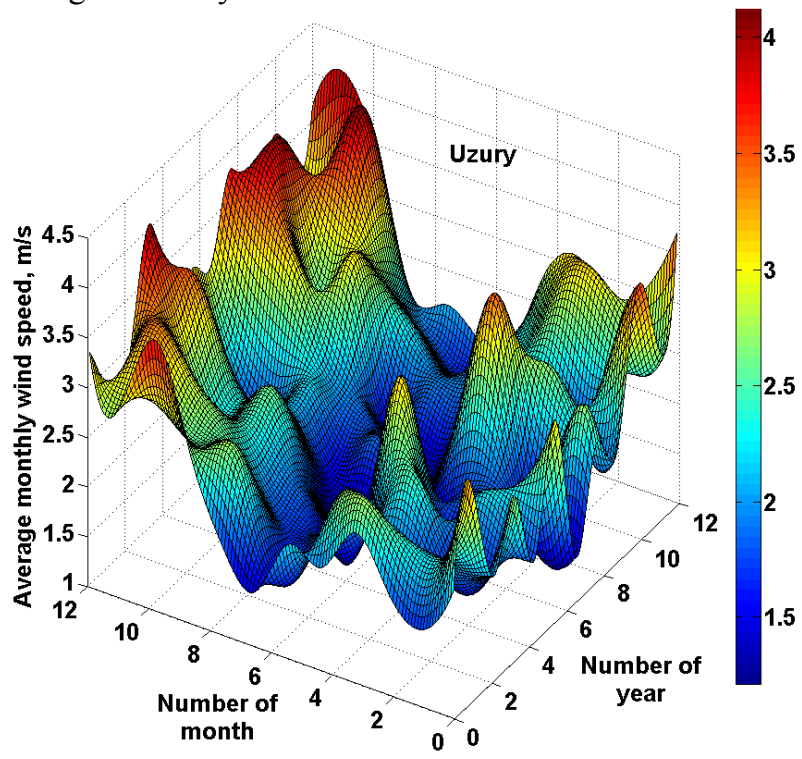

Fig. 3. The average monthly wind speed in the village of Uzury according to 12 years of meteorological observations.

Figure 4 shows the change in air density in the village of Uzury. When calculating air density, air temperature, pressure and humidity are taken into account.

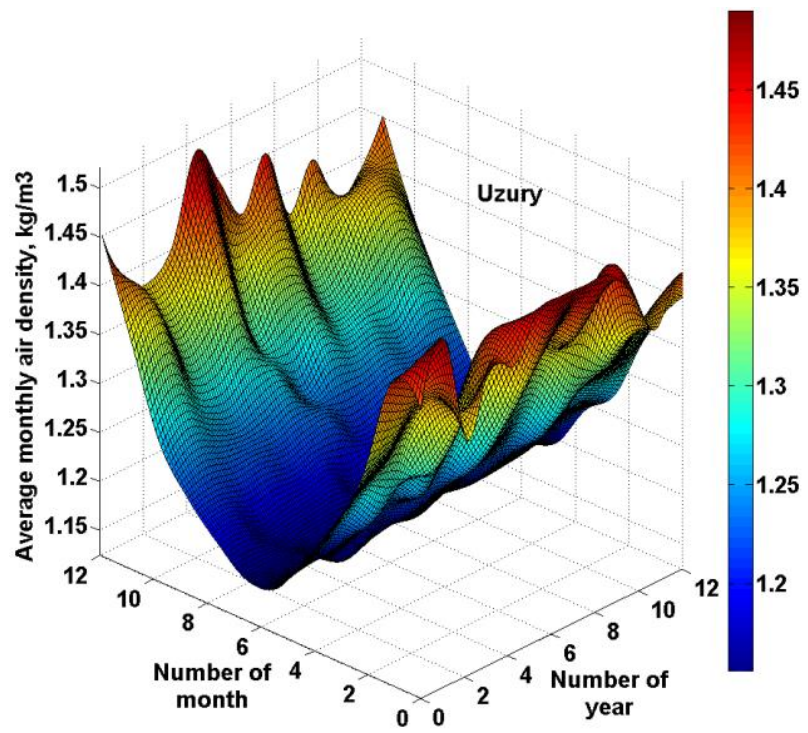

Fig. 4. The average monthly wind speed in the village of Uzury according to 12 years of meteorological observations. 
The obtained values of solar radiation, wind speed, air density, temperature and other parameters can be used to simulate regimes renewable energy sources.

Figures $1-4$ are based on monthly average values. At the same time, average monthly values were obtained based on 730 hours of each month in the year (a total $730 \times 12=8760 \times 12=105120$ values $)$.

\section{Conclusion}

The article briefly presents the method and algorithm for preparing initial climatic information for system energy research with renewable energy sources. The presented method is based on long-term meteorological observations.

The study uses a software «Local analysis of environmental parameters and solar radiation». The village of Uzury located on Olkhon Island in the central part of Lake Baikal was chosen as an example.

Formed array of initial meteorological information has a dimension of $10 \times 105120$.

This array of initial climatic information may be used to solve the following tasks with renewable energy sources.

- Simulation of solar and wind power plants [6].

- Optimization of the installed capacity of renewable energy sources [6].

- Problems of reliability and stability of energy systems $[7,8]$.

- Economics of renewable energy.

- Electrical load forecast based on detailed climate information

- Development of distributed generation.

The work was performed as part of the scientific program III.17.1. Siberian Branch of the Russian Academy of Sciences. Scientific project number AAAAA17-117030310433-6

\section{References}

1. RP5.ru - URL: http://rp5.ru

2. Wong L.T., Chow W.K. Solar radiation model. Applied Energy, 2001, vol. 69, 191-224.

3. Kasten F., Czeplak G. Solar and terrestrial radiation dependent on the amount and type of cloud. Solar Energy, 1980, vol. 24, 177-189.

4. Karamov D.N. Mathematical modeling of solar radiation based on open access long-term meteorological observation data. Bulletin of the Tomsk Polytechnic University. Geo Assets Engineering, 2017, vol. 328, no. 6, 28-37. In Rus.

5. Karamov D.N. Formation of initial meteorological arrays with the use of long-term series FM 12 Synop and METAR in systems energy studies. Bulletin of the Tomsk Polytechnic University. Geo Assets Engineering, 2018, vol. 329, no. 1, 69-88. In Rus.

6. Karamov D.N. Mathematical modelling of an autonomous power supply system using renewable energy sources. Bulletin of Irkutsk State Technical University, 2015, vol. 104, no. 9, 133-140. In Rus.

7. Karamov D.N., Naumov I.V., Perzhabinsky S.M. Mathematical modelling of failures of electrical grid $(10 \mathrm{kv})$ of autonomous energy systems with renewable distributed generation. Bulletin of the Tomsk Polytechnic University. Geo Assets Engineering, 2018, vol. 329, no. 7, 116-130. In Rus.

8. Karamov D.N., Perzhabinsky S.M. Adequacy analysis of electric power systems with wind and solar power stations. E3S Web of Conferences 58, 02019 (2018). 